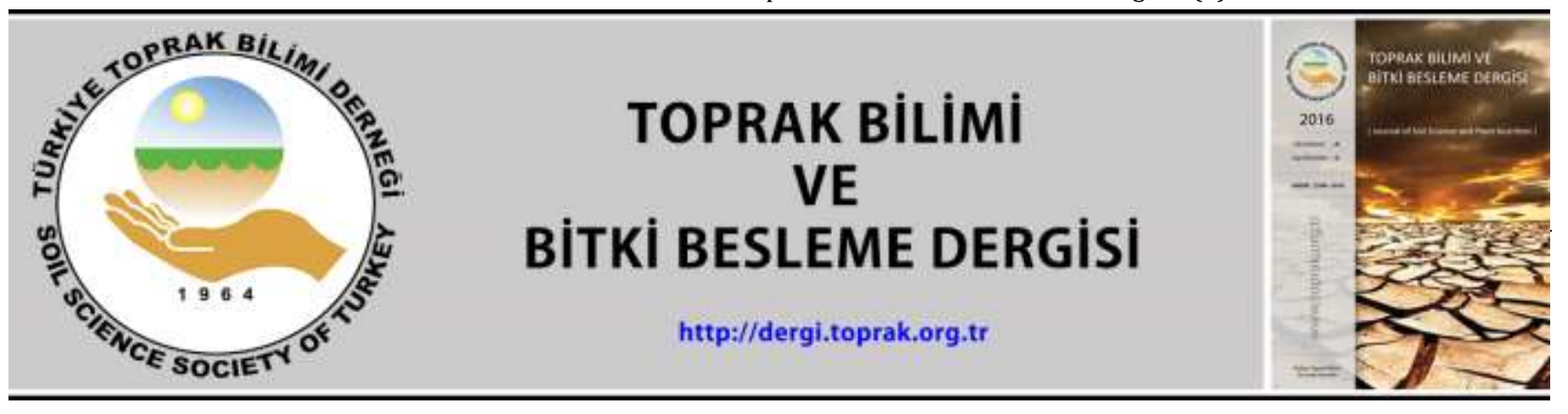

\title{
Komşu iki mikro havzada erozyon duyarlılık değerlerinin arazi örtüsü ve arazi kullanımına bağlı değişimin belirlenmesi
} ๑Ali İmamoğlu 1,*, ๑ Orhan Dengiz ${ }^{2}$

\author{
${ }^{1}$ Nevşehir Hacı Bektaş Veli Üniversitesi, Fen Edebiyat Fakültesi, Coğrafya Bölümü, Nevşehir \\ ${ }^{2}$ Ondokuz Mayıs Üniversitesi, Ziraat Fakültesi, Toprak Bilimi ve Bitki Besleme Bölümü, Samsun
}

\begin{abstract}
Özet
Erozyon risk durumlarının belirlenmesine yönelik toprak duyarlılık indekslerinin kullanılması, özelikle erozyon araştırmalarında önemli yer teşkil etmektedirler. Toprağın erozyona duyarlılığı, yağış veya yüzey akışla toprağın parçalanmaya direncidir. Bu çalışmanın amacı, Gediz havzası içerisinde yer alan yaklaşık $16.6 \mathrm{~km}^{2}$ alan kaplayan Ilıcak ve Kum Çayı iki bitişik mikro havzada dağılım gösteren toprakların strüktür stabilite indeksi, agregat stabilitesi ve dispersiyon oranları belirlenerek, arazi örtüsü/arazi kullanımı ile arasındaki ilişkilerin incelenmesidir. Bu çalışmada, Mikro havzalarda dağılım gösteren toprakların erozyona karşı gösterdiği direncin, bazı erozyona duyarlılık indeksleri kullanılarak, arazi kullanım durumuna bağlı değişimleri karşılaştırılmıştır. Arazi çalışmaları yanında, uydu verileri, sayısal arazi yükselti modeli, ve sayısal jeoloji haritaları gibi toprak ve arazi kullanımı ile ilişkili veriler uzaktan algılama ve coğrafi bilgi sistemleri ile analiz edilmiştir. Çalışma alanı 700m x 700m grit aralıklarına bölünerek 0-30 cm derinlikten ekili alanlarda 186 örnek, orman alanlarından 74 örnek mera alalarından ise 59 örnek ile toplam 319 adet toprak örnekleri alınmıştır. Alına örneklerde bazı fiziksel ve kimyasal analizler yapılarak, toprakların asma tarımı için uygunluk aralık değerleri belirlenmiştir. Toprakların bünyeleri kum, tınlı kum ve kumlu tınlı arasında değişmekte olup hafif alkali ve hafif asit reaksiyonludur. Elde edilen sonuçlara göre ekili alanlardaki dispersiyon oranı ve agregat stabilitesi ortalamanın altında değ erler gösterirken strüktür stabilite indeksi değeri özellikle tarım alanlarda erozyona karşı oldukça duyarlı oldukları belirlenmiştir.
\end{abstract}

Anahtar Kelimeler: Arazi kullanımı/arazi örtüsü, Mikro havza, Toprak aşınabilirliği.

\section{Determination of relationship between situation of soil erosion sensitivity indexes and land use/land cover in two adjacent micro catchments}

\begin{abstract}
In order to determine erosion risk cases using soil erodibility indexes, they occupy important place particularly for erosion researches. Soil erodibility is the resistance of soil to detach by rainfall impact or surface flow force. The main aim of this research is determination of relationship between situation of soil erosion sensitivity and land use/land cover in two adjacent micro catchments called Ilıcak and Kum Çay located in Gediz Basin soils. In this study, it was determined erodibility indexes and resistance case of different soils found in two adjacent micro catchments to erosion using some soil structure index, aggregate stability and dispersion ratio to compare their variability each other based on land use and land cover. In addition to field studies, digital soil and land use related (satellite data, DEM and digital geology maps) data were used and analysed with remote sensing and geographic information systems techniques. The study site was divided into $700 \mathrm{~m} \times 700 \mathrm{~m}$ grid squares. The total of 319 grid points was obtained and 319 soil samples were collected from surface soil $(0-30 \mathrm{~cm})$ depths of each grid centre located on crop land (186), forest land (74) and pasture land (59). Soil textures of the study area vary from sand to sandy lam and loamy sand and their soil reaction changes between slightly alkaline and acid. According to obtained results, values of soil structure index, aggregate stability and dispersion ratio were found low level as erodiable soil particularly in crop lands.

Keywords: Land use/land cover, Micro catchment, Soil erodibility.
\end{abstract}

(C) 2020 Türkiye Toprak Bilimi Derneği. Her Hakkı Saklıdır

\section{Giriș}

Türkiye, arazi varlığının önemli bir kısmı eğimli arazilerden oluşan bir ülkedir. Bu sebeple ülkemizde toprak koruma ve yönetimi oldukça hassas bir konudur. Bu nedenle toprakların fiziksel özelliklerinin iyileştirilmesi özellikle tarımsal anlamda ve toprak varlığının korunması açısından bir zorunluluktur. Toprakların fiziksel özelliklerinin geliştirilerek strüktür stabilitelerinin artırılması, toprakta iletkenliğin artışına, profilde normal su rejiminin düzelmesine ve bitkiye elverişli duruma gelmesine olanak sağlamaktadır (Özdemir ve ark.,

\section{* Sorumlu yazar:}

Tel. : $\quad 05448606866$

E-posta : aliimamoglu@yandex.com
Geliș Tarihi

Kabul Tarihi
10 Ekim 2019

20 Mayis 2020
e-ISSN

DOI
2146-8141

10.33409/tbbbd.757017 
2015). Yine yapılan bir araștırmaya göre strüktürel bakımdan gelişmiş bir toprakta havalanma ve su tutma kapasitesinin artması yanında, bitki besin elementlerinin alımı kolaylaşmakta ve erozyona karşı dayanıklılık artmaktadır (Turgut ve Aksakal, 2010). Bu sebeple fiziksel parametrelerin hangi arazi kullanım şartlarında nasıl değişiklik gösterdiği konusu incelenmesi gereken önemli bir konudur. Toprakların agregat büyüklük dağılımları ve stabilite ölçümleri fiziksel özellikler olmasına rağmen, toprakların bir kalite göstergesi olarak kabul edilmektedir (Candemir ve Gülser, 2011; Gülser ve ark. 2015). Ayrıca agregat stabilitesi ölçümleri toprak agregatlarının bozulmayı oluşturan çevresel etmenlere karşı direncinin belirlenmesinde önemli bir parametre olarak kullanılmaktadır (Gülser 2004; Eraslan ve ark., 2016).

$\mathrm{Bu}$ çalışmanın amacı, Gediz havzası içerisinde yer alan yaklaşık 16.6 km2 alan kaplayan Ilıcak ve Kum Çayı iki bitişik mikro havzada dağılım gösteren toprakların strüktür stabilite indeksi, agregat stabilitesi ve dispersiyon oranları belirlenerek, arazi örtüsü/arazi kullanımı ile arasındaki ilişkilerin incelenmesidir.

\section{Materyal ve Yöntem}

\section{Materyal}

\section{Araştırma sahasının yeri ve sınırları}

Araştırma sahası Gediz Havzası içerisinde bulunan iki mikro havzadan oluşmaktadır. Yaklaşık 16.500 hektar olan çalışma alanı, deniz seviyesinden $70 \mathrm{~m}$ ile $760 \mathrm{~m}$ arasında yükselti değişimine sahiptir. Manisa ilinin Akhisar ilçesi sınırları içerisinde bulunmaktadır. Havza alanının genel arazi örtüsü ve arazi kullanımları sulu tarım, kuru tarım, maki, çalılık arazi, orman, yerleşimler, çıplak ve kumluk alanlardır.
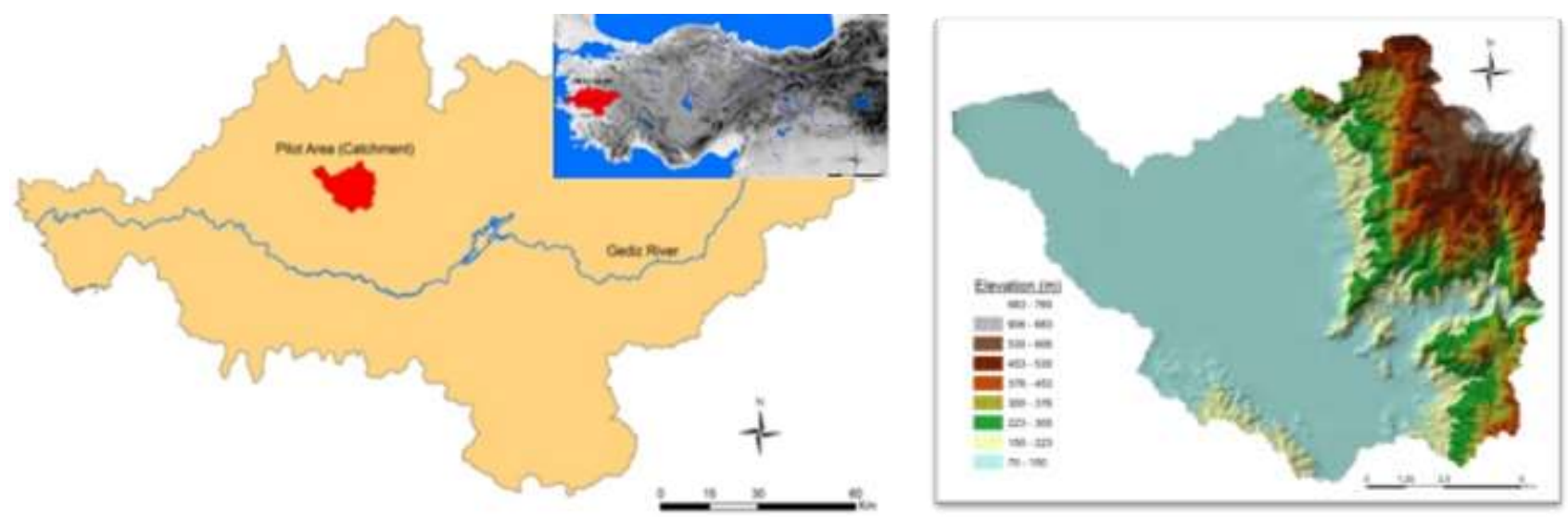

Şekil 1. Araştırma sahası lokasyon ve yükselti haritası

Araştırma sahasında ortalama sıcaklık değerleri yıllık $13.5^{\circ} \mathrm{C}-16.6^{\circ} \mathrm{C}$ arasında ve ortalama yağış değeri ise yıllık 450-1060 mm arasında değişmektedir. Havzanın yıllık yağış ortalaması $603 \mathrm{~mm}$ 'dir. Yıllık ortalama sıcaklık değeri $15.9^{\circ} \mathrm{C}$ civarındadır. Ortama sıcaklıklar $0{ }^{\circ} \mathrm{C}$ nin altına düşmemektedir. Kış aylarında ortalama sıcaklık değerleri $8{ }^{\circ} \mathrm{C}$ nin üzerindedir. Sıcaklıkların arttığı yaz aylarında ise ortalama sıcaklık değerleri $25^{\circ} \mathrm{C}$ nin üzerinde görülmektedir. Bölgede en sıcak geçen ayların Temmuz ve Ağustos ayları olduğu gözlenmiştir.

\section{Yöntem}

\section{Toprak Örnek Alımı ve Analizleri}

Alan 700m x 700m şeklinde oluşturulan grit sisteminden yüzeyden $(0-30 \mathrm{~cm}) 319$ adet toprak örneklemesi yapılmıştır. Toprak örneklemesine ait desen Şekil 2'de verilmiştir. Toprak örnek noktaları farklı topoğrafik konumlar ve arazi kullanımları/arazi örtüsü tipleri göz önüne alınarak belirlenmiştir.

Ekili alanlarda 186 örnek, orman alanlarından 74 örnek mera alalarından ise 59 örnek alınmıştır. Bünye (Tekstür): Hidrometre yöntemi kullanılarak (Bouyoucous, 1951), Kireç: Serbest karbonatların tayininde Scheibler kalsimetresi kullanılarak (Soil Survey Staff, 1993), Toprak reaksiyonu (pH): Saturasyon çamurunda cam elektrotlu pH metre kullanarak (Soil Survey Staff, 1992), Elektriksel iletkenlik: Saturasyon çamurunda kondaktivimetre aleti kullanılarak (Soil Survey Staff, 1992), Organik madde: Walkley-Black yönteminin Jackson tarafından modifiye edilmiş şekli ile yapılmıştır (Jackson, 1958). Agregat stabilitesi (AS) Yoder tipi eleme setinde sslak eleme yöntemine göre belirlenmiştir (Kemper ve Rosenau, 1986). Suya Dayanıklı Agregat Stabilitesi (SAD): Yoder tipi eleme setinde ıslak eleme yöntemine göre belirlenmiştir (Kemper ve Rosenau, 1986). 
Strüktür Stabilite Indeksi (SSI): Strüktür değeri, hidrometre ölçümlerine dayanılarak ve aşağıdaki eşitlik kullanılarak bulunmuştur (Leo, 1963).

$\mathrm{S}=\Sigma \mathrm{n}-\Sigma \mathrm{b}$ S= dayanıklılık ölçütü

$\Sigma \mathrm{n}=$ Mekanik analizle elde edilen silt ve kil fraksiyonları toplamı

$\Sigma \mathrm{b}=$ Agregatlardan süspansiyona dispers olan silt ve kil fraksiyonları toplamı.

Dispersiyon oranı (DO): Süspansiyonda dispers edilmeden ölçülen silt+kil \% değerinin, mekanik analizde ölçülen silt+kil \% değerine oranlanmasıyla hesaplanmıştır (Lal, 1988).

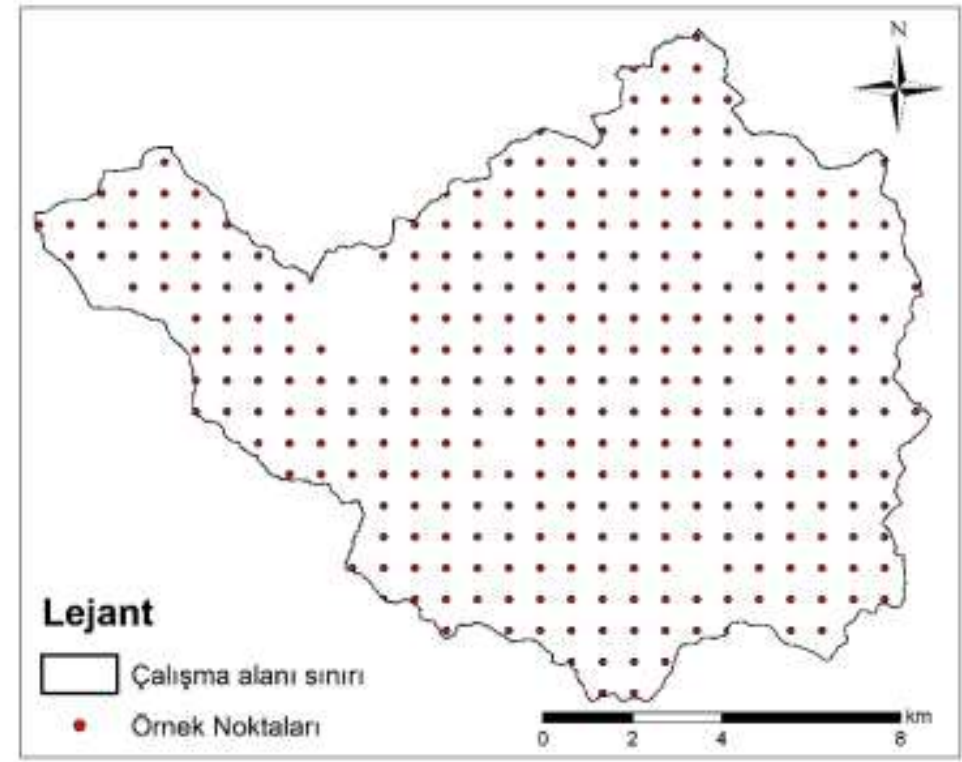

Şekil 2. Toprak Örnek deseni

\section{Tanımsal ve jeoistatistiksel yöntemler}

Verilerin analizinde SPSS 20.0 yazılımı kullanılmıștır. Örnekleme yapılan alanlardaki toprak özelliklerinin en büyük, en küçük, standart sapma, varyasyon katsayısı, ortalama, çarpıklık ve basıklık değerleri şeklindeki ait tanımlayıcı parametreler SPSS programı ile hesaplanmıștır. Jeoistatistik alansal dağılım haritalarının elde edilmesinde ise ArcGIS 9.3v yazılımından yararlanılmıştır. ArcGIS 10.2.2 Geosatistical Extension” program, üretilen haritalarda (ME) tahminin ortalama hatası ve (RMSE) tahminin standardize ortalama hatalar karekökü kriterlerini kullanmaktadır.

$$
R M S E=\sqrt{\frac{\sum\left(z_{i^{*}}-z_{i}\right)^{2}}{n}}
$$

Eşitlikte;

$Z_{i}$ : tahmin edilen değer, $Z_{i^{*}}$ ölçülen değer ve ${ }^{n}$ örnek sayısını ifade etmektedir.

Her bir modelin RMSE değeri belirlenmiştir. Modellere ait RMSE değerleri Çizelge Çizelge 5'de verilmiştir.

\section{Bulgular ve Tartışma}

\section{Havzanın topoğrafik özellikleri}

Araştırma sahasının batı kesiminde alüvyon sahaların yayılış gösterdiği geniş ovalık alanlar görülmektedir. Bu kesim verimli alanlardır. Öte yandan havzanın doğu ve kuzey-doğu kesimleri dağllk ve tepelik arazilerden oluşmaktadır. Buralarda eğim değerleri oldukça yüksektir. \%45 eğim değerlerinin görüldüğü vadiler bulunmaktadır (Şekil 3). 


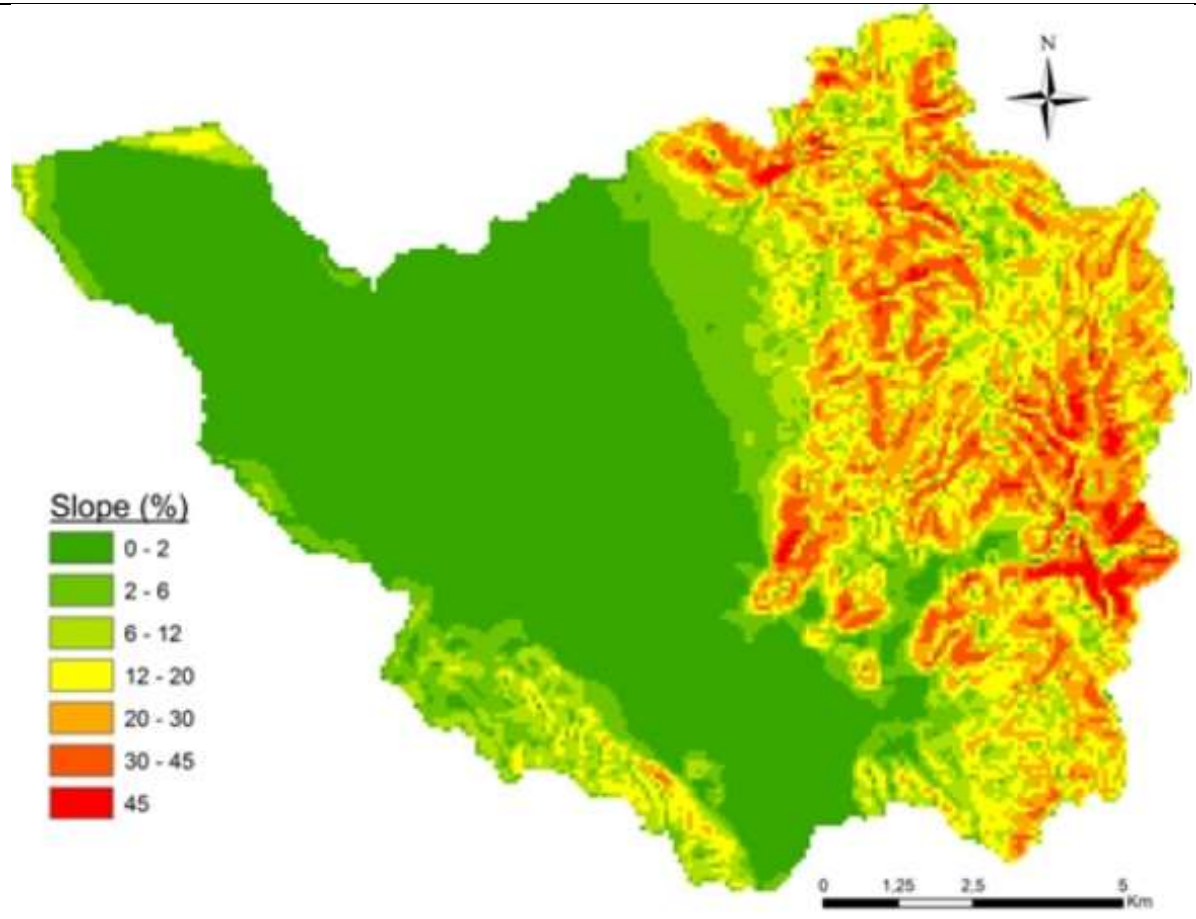

Şekil 3. Araştırma sahası eğim haritası.

\section{Havzanın arazi kullanımı ve arazi örtüsü}

Çalışma alanının 2015 yılına ait Landsat uydu görüntüsü kullanılarak araştırma sahasının arazi kullanımı ve arazi örtüsü sınıflandırması yapılmıştır. Elde edilen haritaya göre dağılım genel olarak sulu tarım (pamuk, üzüm, darı, domates, patates, karpuz vs), kuru tarım (zeytin, tütün, buğday, arpa vs), maki, çalılık arazi, orman, yerleşimler, hava alanı, çıplak ve kumluk alanları şeklindedir. Çalışma alanı içerisinde dağılım gösteren Arazi kullanımı/Arazi örtüsü (AK/AÖ) türlerinin alansal ve oransal dağılımları Çizelge 1'de verilmiştir. Buna göre yamaçların etek kısımlarında sulanmayan karışık tarım alanları, eğimin hafif ve düze yakın olduğu alçak alanlarda sulanabilir tarım alanlar geniş yer kaplar.

Çizelge 1. Arazi kullanım/arazi örtüsü türlerinin alanları

\begin{tabular}{|c|c|c|}
\hline & Alan & Oran \\
\hline Arazi kullanımı/Arazi örtüsü (AK/AÖ) türü & ha & $\%$ \\
\hline Kesikli kırsal & 1854,9 & 1,1 \\
\hline Havaalanları & 3564 & 2,1 \\
\hline Mineral çıkarım sahaları & 939,6 & 0,6 \\
\hline İnşaat sahaları & 615,6 & 0,4 \\
\hline Sulanmayan ekilebilir alan & 356,4 & 0,2 \\
\hline Sulanan alan & 51281,1 & 30,8 \\
\hline Üzüm bağları & 7711,2 & 4,6 \\
\hline Zeytinlikler & 8415,9 & 5,1 \\
\hline Meralar & 1061,1 & 0,6 \\
\hline Sulanmayan karıșık tarım & 14588,1 & 8,8 \\
\hline Meyveyle karışık sulu & 8189,1 & 4,9 \\
\hline Doğal bitki örtüsü ile birlikte bulunan tarım alanları & 4608,9 & 2,8 \\
\hline Geniș yapraklı ormanlar & 591,3 & 0,4 \\
\hline İğne yapraklı ormanlar & 24615,9 & 14,8 \\
\hline Karışık ormanlar & 4544,1 & 2,7 \\
\hline Doğal çayırlıklar & 8618,4 & 5,2 \\
\hline Sklerofil bitki örtüsü & 4746,6 & 2,9 \\
\hline Bitki değişim alanları & 16767 & 10,1 \\
\hline Sahiller, kumsallar ve kumluklar & 2673 & 1,6 \\
\hline Seyrek bitki alanları & 704,7 & 0,4 \\
\hline Toplam & 166446,9 & 100,0 \\
\hline
\end{tabular}




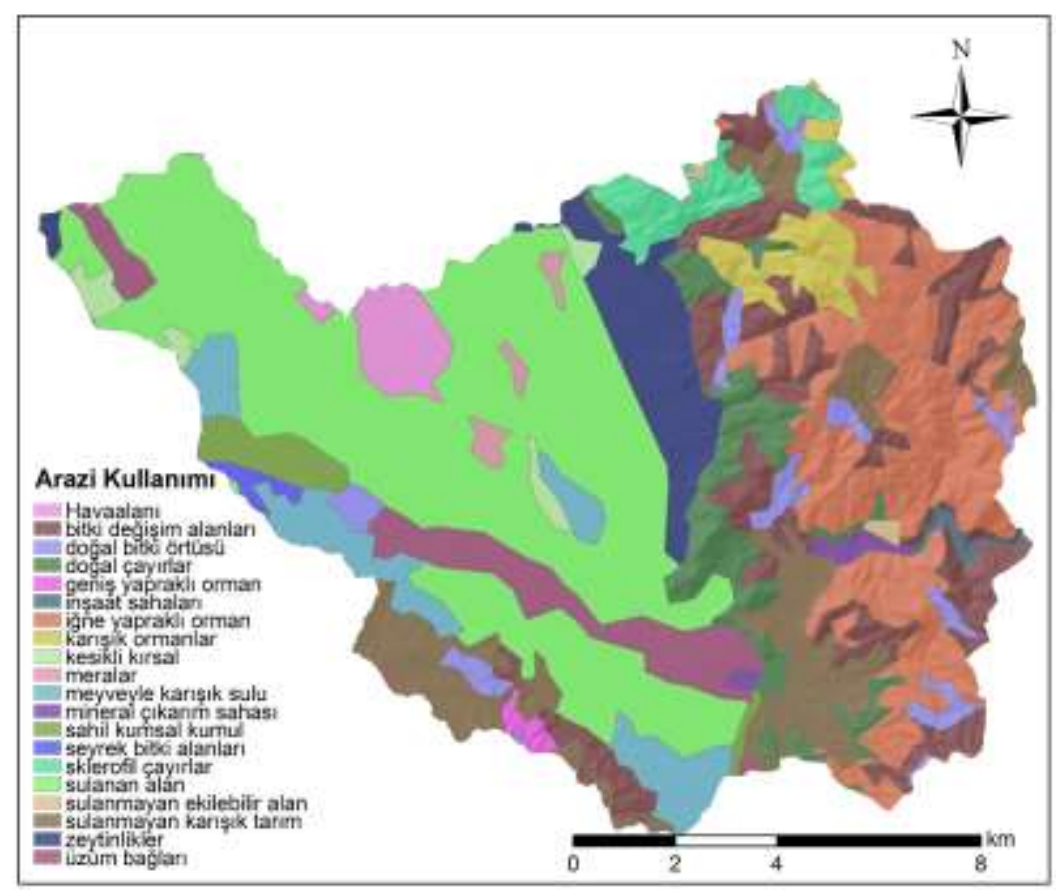

Şekil 4. Arazi kullanım haritası.

\section{İstatistiksel değerlendirme}

Araştırma sahasından alınan toprak örneklerinde toprakların bazı fiziksel ve kimyasal özellikleri incelenmiştir. $\mathrm{Bu}$ özelliklerin tanımlayıcı istatistiksel hesaplamaları yapılmıștır. Toprak fiziko-kimyasal özelliklerine ait tanımlayıcı istatistikler Çizelge 2'de verilmiştir. Elde edilen sonuçlara göre SSI 1,09 ile 68.16 arasında değerler gösterirken ortalaması 33.39 değeri bulunmuştur. Yine DO en yüksek değeri 106.9,AS en yüksek değeri ise 80 çıkmıştır.

Çizelge 2. Toprak örneklerinin tanımsal istatistikleri.

\begin{tabular}{lllllllllll}
\hline & kil & silt & kum & ph & ec & om & caco & ssi & do & as \\
\hline ortalama & 6,15 & 8,46 & 85,38 & 7,32 &, 6653 & 2,12 & 10,53 & 33,33 & 32,08 & 21,08 \\
Median & 4,95 & 6,06 & 88,20 & 7,30 &, 6500 & 1,87 & 6,52 & 33,73 & 29,84 & 14,14 \\
Std. sapma & 4,10 & 6,32 & 9,68 & 0,26 & 0,25 & 1,18 & 10,61 & 13,27 & 15,91 & 18,4 \\
Varyans & 16,83 & 39,9 & 93,79 & 07 & 0,063 & 1,41 & 112,75 & 176,2 & 253,42 & 341 \\
En düš̈uk değer & 0,83 & 0,48 & 39,41 & 6,55 & 0,22 & 0,13 & 0,59 & 1,09 & 2,77 & 0,62 \\
En yüksek değer & 29,25 & 36,85 & 98,67 & 8,28 & 1,83 & 5,53 & 76,94 & 68,16 & 106,90 & 80 \\
\hline
\end{tabular}

n: 319

Ekili alanlarda 186 örnek, orman alanlarından 74 örnek mera alalarından ise 59 örnek alınmıştır. Ekili alanlardaki dispersiyon oranı ve AS ortalamanın altında değerler gösterirken SSI değeri ekili alanlarda oldukça düşük çıkmıştır. Orman ve mera alanlarında ise DO ve AS ortalamanın altında iken SSI ortalamanın üzerinde değerler göstermiştir.

Çizelge 3. Arazi kullanım türlerine göre bazı parametrelerin ortalama değerleri.

\begin{tabular}{lllccc}
\hline AK/AÖ & Örnek sayısı & Örnek oranı (\%) & DO (ort) & AS (ort) & SSI (ort) \\
\hline ekili alan & 186 & 58,3 & 37,9 & 13,52 & 29,66 \\
orman & 74 & 23,2 & 23,04 & 33,14 & 38,96 \\
mera & 59 & 18,5 & 25,62 & 29,31 & 38,22 \\
toplam & 319 & & & & \\
\hline
\end{tabular}

Tarım yapılan alanlar da kendi içerisinde karşılaştırmaya tabi tutulmuştur. Ortalama değerlerin tarım alanları içerisindeki oranları her bir arazi kullanımı üzerine düşen nokta sayısının yüzde oranı hesaplanarak karşılaştırılmıştır. Burada yapılan istatistiki değerlendirme sonucu tarım alanları içerisinde dispersiyon oranını alanın genel ortalamada yüksek olmasına rağmen sulanmayan alanlarda 19,76 ile DO oldukça düşüktür. AS değerleri ise sulanmayan ekilebilir alanlarda oldukça yüksek, zeytinliklerde ise ortalamanın üzerinde değer göstermektedir. SSI ise ekili alanlarda görülen ortalama değerlere yakın değerler göstermektedir. 


\begin{tabular}{llllll}
\hline \multicolumn{6}{l}{ Cizelge 4. Erozyon duyarlılık parametrelerinin tarım alanlarındaki ortalama dağılımı. } \\
\hline & örnek sayısı & Örnek oranı (\%) & do (ort) & as (ort) & SSı (ort) \\
\hline meyveyle karışıı sulu tarım & 17 & 9,1 & 42,16 & 8,36 & 22,19 \\
sulanamayan sera & 101 & 54,3 & 39,83 & 13,31 & 31,69 \\
sulanmayan ekilebilir alan & 1 & 0,5 & 19,76 & 62,88 & 43,38 \\
sulanmayan karışık tarım & 33 & 17,7 & 28,33 & 14,56 & 34,55 \\
üzüm bağları & 17 & 9,1 & 41,04 & 10,48 & 20,89 \\
zeytinlikler & 17 & 9,1 & 25,77 & 24,62 & 39,57 \\
\hline
\end{tabular}

\section{Jeoistatistiksel dağılış ve değerlendirme}

Her bir noktaya ait DO, AS ve SSI oranlarına ait alansal dağılımların en iyi şekilde temsil edilebilmesi amacıyla 14 ayrı enterpolasyon modeli uygulanmış olup, bu modellerden hata kareler ortalaması (RMSE) en düşük olan değerler seçilmiştir (Çizelge 5).

Çizelge 5. Jeoistatistiksel modeller ve uygun RMSE değerleri

\begin{tabular}{|c|c|c|c|c|c|}
\hline \multicolumn{3}{|l|}{ Jeoistatistiksel Yöntemler } & DO & AS & SSI \\
\hline \multirow{3}{*}{ Inverse Distance Weighting } & \multirow{3}{*}{ IDW } & 1 & 13,78 & 16,03 & 11,82 \\
\hline & & 2 & 13,97 & 16,07 & 11,8 \\
\hline & & 3 & 14,27 & 16,2 & 11,88 \\
\hline \multirow{2}{*}{ Radial Basis Functions } & \multirow{2}{*}{ RBF } & Completely Regularized Spline & 14,43 & 16,26 & 11,82 \\
\hline & & Thin Plate Spline & 17,23 & 17,81 & 12,8 \\
\hline \multirow{9}{*}{ Kriging } & \multirow{3}{*}{ Ordinary Kriging } & Spherical & 13,86 & 15,99 & 11,93 \\
\hline & & Exponential & 13,85 & 15,99 & 11,88 \\
\hline & & Gaussian & 13,95 & 16,03 & 12,03 \\
\hline & \multirow{3}{*}{ Simple Kriging } & Spherical & 13,84 & 15,94 & 11,9 \\
\hline & & Exponential & 13,84 & 15,95 & 11,83 \\
\hline & & Gaussian & 13,94 & 15,98 & 12 \\
\hline & \multirow{3}{*}{ Universal Kriging } & Spherical & 13,86 & 15,99 & 12,8 \\
\hline & & Exponential & 13,85 & 15,99 & 11,93 \\
\hline & & Gaussian & 13,95 & 16,03 & 11,88 \\
\hline
\end{tabular}

Dispersiyon oranı topraktaki doğal agregatların su ile temas ettiğinde çözülme (dispersleşme) derecesini gösteren bir göstergedir. Dispersiyon oranı ıslanma sonucunda toprak strüktüründeki bozulmayı yansıtmaktadır. Bu oranının azalması toprakların erozyona karşı dayanıklılıklarının arttığını göstermekte ve \%15'den küçük orana sahip topraklar erozyona karşı dayanıklı olarak kabul edilmektedir (Lal, 1988). Bu sınır değerlerine göre, araştırma sahası topraklarının erozyona karşı dayanıklı olmadığı, sadece sulanmayan ekilebilir alanlarda tehlike boyutunun düşük olduğu sonucu ortaya çıkmaktadır. Erol ve ark. (2009) Isparta yöresinde bir havzada yaptıkları çalışmada dispersiyon oranlarını orman, tarım ve mera topraklarının tamamında \%15'den büyük olarak bulmuş ve toprakları erozyona dayanıksız diye nitelendirmiştir. Çalışmada elde edilen sonuçlar bu çalışma ile benzerlik göstermektedir (Şekil 5).

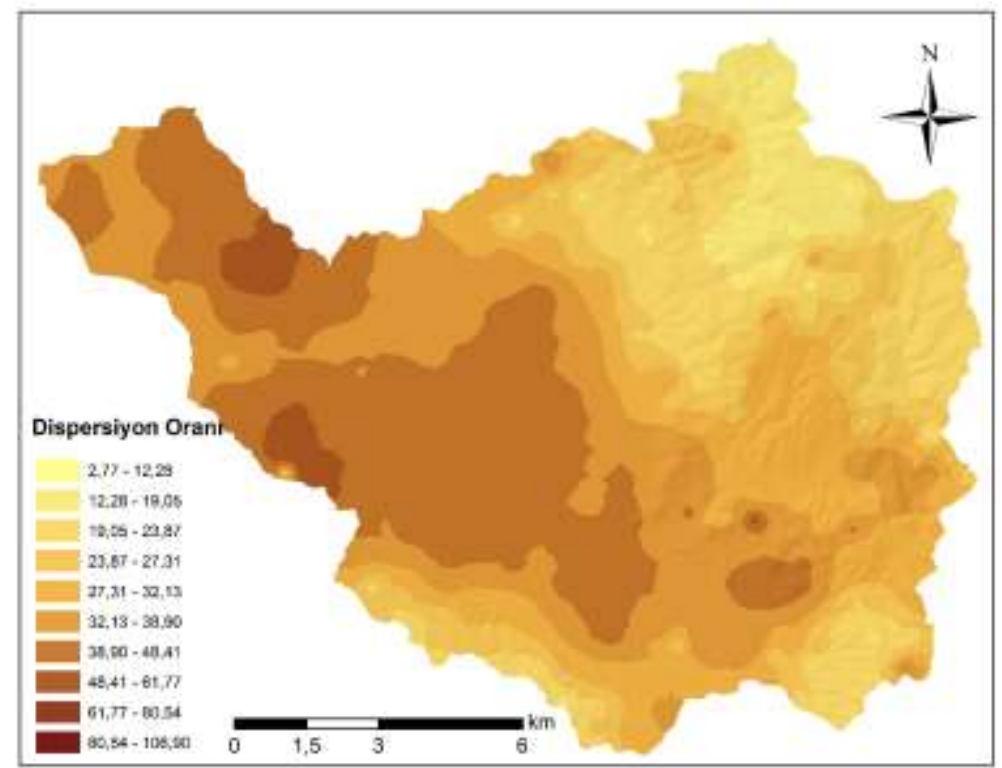

Şekil 5. Araştırma sahası dispersiyon oranı dağılımı. 
Agregat stabilitesinin orman alanlarında çıkan değerlerine bakıldığında ortalamanın üzerinde olduğu görülmüștür. Kanar ve Dengiz (2015) yaptıkları çalıșmada agregat stabilitesinin orman alanlarında daha düşük değerlerde olduğu sonucuna varmıștır. Burada çıkan farklılık orman örtüsünün farklılığı ile ilgili olduğu düşünülmektedir. Araştırmacıların yaptığı çalışmada orman alanları geniş yapraklı bireylerden oluşurken, Bu çalışmada orman sahaları genellikle iğne yapraklı ya da bozuk meşelik alanlardır (Şekil 6).

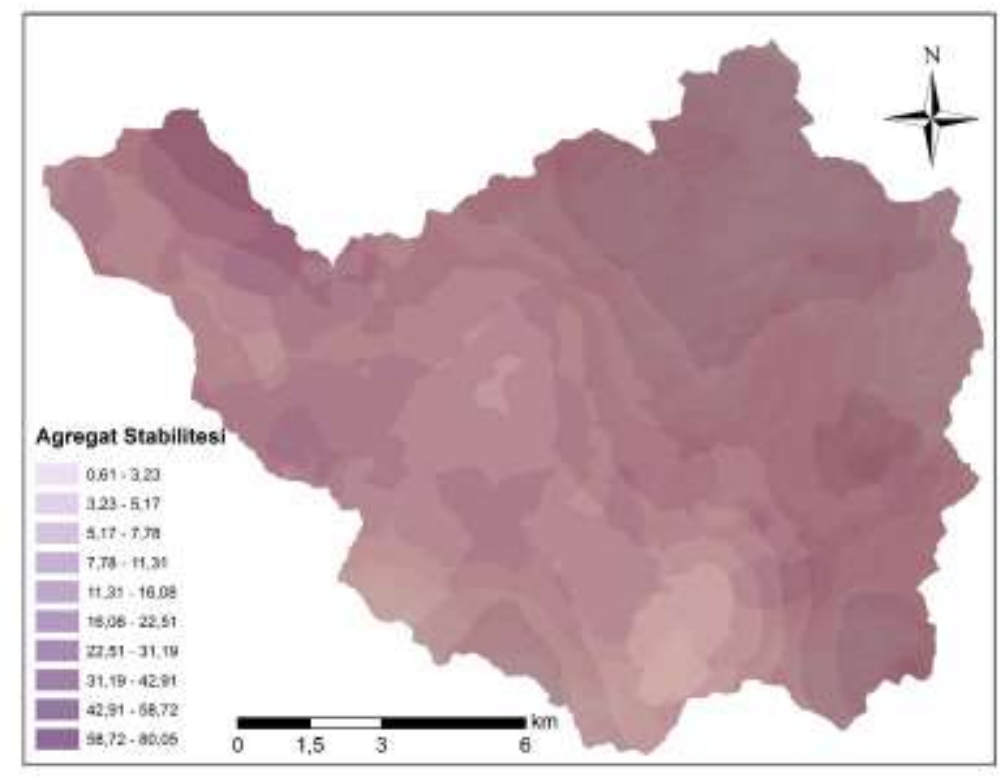

Şekil 6. Araştırma sahası agregat stabilitesi dağılımı.

Atalay'a (2006) göre, toprak tekstürü, toprakta bulunan parçacıkların boyutunu verir; strüktür ise toprak parçacıklarının bir araya gelerek oluşturduğu sıralanma ve bunların duruş biçimini belirler. Bu bağlamda strüktür (yapı), kum, silt ve kilden ibaret toprak parçacıklarının birleşme (agregasyon) özelliklerini veya bunların küme, demet halini alma biçimlerini içerir. Yapılan çalışmalarda strüktür stabilitesinin özellikle erozyon miktarı üzerinde etkili olduğu görülmüştür (Şekil 7). Erozyonun önlenmesinde strüktür stabilite değerlerini yükseltmek için çeşitli çalışmalar yapılmış ve özellikle organik gübre kullanımının önemine dikkat çekilmiştir (Erkol ve ark, 1993; Turgut ve Aksakal, 2010).

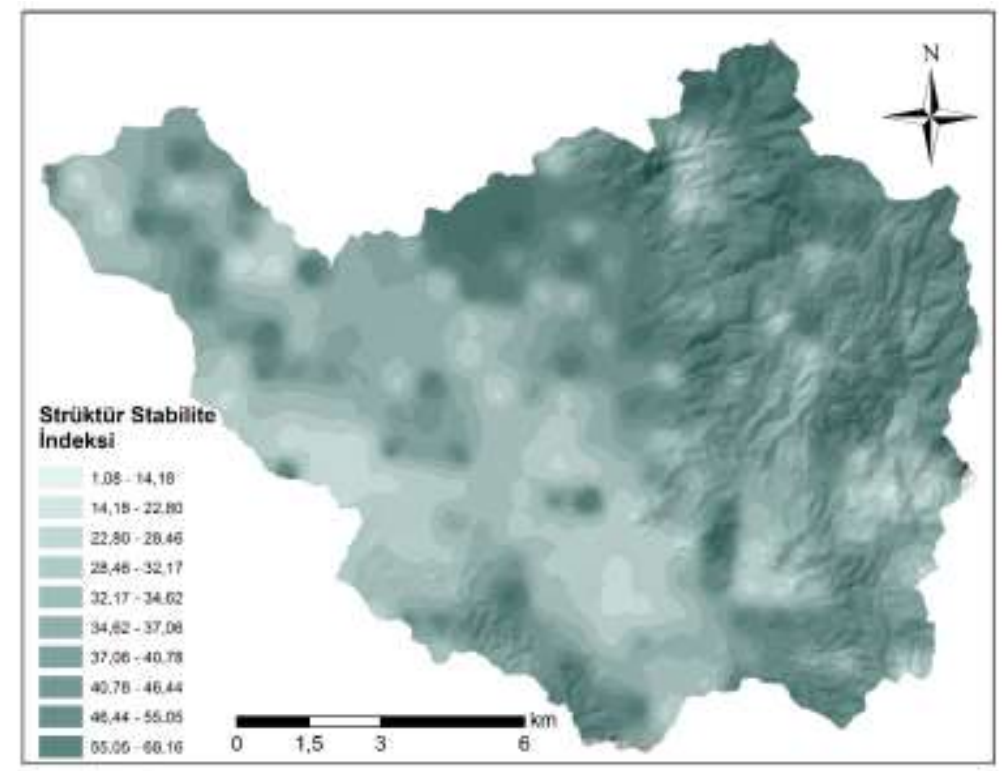

Şekil 7. Araştırma sahası strüktür stabilite indeksi dağılımı.

\section{Sonuç}

Araştırma sahasında 319 adet örnek alınmıştır. Bu örneklerin alındığı arazi kullanım çeşitleri ekili alan, orman ve mera olmak üzere üç kısımda sınıflandırılmıştır. Ekili alanlarda 186 örnek, orman alanlarından 74 örnek mera alalarından ise 59 örnek alınmıştır. Ekili alanlardaki DO ve AS ortalamanın altında değerler gösterirken SSI değeri ekili alanlarda oldukça düşük çıkmıștır. Orman ve mera alanlarında ise dispersiyon oranı ve AS ortalamanın altında iken SSI ortalamanın üzerinde değerler göstermiştir. Tarım yapılan alanlar 
da kendi içerisinde karşılaştırmaya tabi tutulmuştur. Yapılan istatistik sonucu tarım alanları içerisinde dispersiyon oranını alanın genel ortalamada yüksek olmasına rağmen sulanmayan alanlarda 19, 76 ile Dispersiyon oranı oldukça düşüktür. Agregat stabilitesi değerleri ise sulanmayan ekilebilir alanlarda oldukça yüksek, zeytinliklerde ise ortalamanın üzerinde değer göstermektedir. Strüktür stabilitesi ise ekili alanların genelinde görülen ortalama değerlere yakın değerler göstermektedir.

Çalışma alanının tarımsal üretim faaliyetleri yapılan yüzey topraklarında aşırı toprak işleme, gübreleme, sulama gibi uygulamaların da yapılması kaçınılmazdır. Ancak bu uygulamaların aşırı yapılması toprak yapısının bozulmasina sebep olmaktadır.

Çalışma alanında toprakların agregat stabilitesi değerini yükseltmek için bitkisel yöntemlere ağırlık verilmelidir. Özellikle bitki ekim nöbeti uygulanmalı, toprağa organik madde takviyesi yapılmalıdır. Toprağı çabuk örten ve uzun süre yüzeyde örtü görevi yapan bitki türleri seçilmelidir.

Araştırma sahasın topraklarının aşınım direncini yükseltmek için dispersiyon oranlarını düşürecek çeşitli toprak düzenleyiciler kullanılmalıdır. Dispersiyon oranı değerleri aşınıma karşı direncin düşük olduğunu göstermektedir.

\section{Teşekkür}

Bu çalışmanın gerçekleştirilmesinde katkıda bulunmalarından dolayı Orman ve Su İşleri Bakanlığı, Çölleşme ve Erozyonla Mücadele Genel Müdürlüğü'ne teşekkür ederiz

\section{Kaynaklar}

Atalay İ, 2006. Toprak oluşumu, sınıflandırılması ve coğrafyası. 3.Baskı, Meta Basım Matbaacılık Hizmetleri, Bornova, İzmir.

Bouyocous GJ, 1951. A recalibration of the hidrometer method for making mechanical analysis of soils. AgronomyJournal, 43; (435-438).

Candemir F, Gülser C, 2011. Effects of different agricultural wastes on some soil quality indexes at clay and loamy sand fields. Comm. Soil Sci. Plant Analy. 42 (1):13-28.

Eraslan S, İmamoğlu A, Coşkun A, Saygın F, Dengiz 0, 2016. İnebolu Havzası Topraklarının Erozyon Duyarlılıklarını Belirlenmesinde Agregat ve Strüktür Stabilite Durumları, Arazi Örtüsü İle Olan İlişkileri. TÜCAUM Uluslararası Coğrafya Sempozyumu International Geography Symposium 13-14 Ekim 2016 /13-14 October 2016, Ankara.

Erkol İ, Demirci N, Şentürk M, Ulusu F, Çoban A, 1993. Toprağa Karıştırılan Organik Artıkların Toprağın Strüktürü ve Aşınıma duyarlılığı Üzerine Etkileri. Atatürk Üniversitesi Ziraat Fakültesi Erzurum.

Erol A, Babalık AA, Sönmez K, Serin N, 2009. Isparta-Darıderesi Havzası Topraklarında Erozyona Duyarlılı̆̆ın Arazi Kullanım Şekillerine Bağlı Değișimi. Süleyman Demirel Üniversitesi Orman Fakültesi Dergisi, Sayı: 2, Yıl: 2009, Sayfa: 21-36.

Gülser C., Kızılkaya, R., Aşkın, T., Ekberli , İ., 2015. Changes in Soil Quality by Compost and Hazelnut Husk Applications in a Hazelnut Orchard. Compost Science and Utilization, 23:3, 135-141.

Gülser, C., 2004. A Comparison of some physical and chemical soil quality indicators influenced by different crop species. Pakistan J. of Biological Sci., 7(6), 905-911.

Jackson M, 1958. Soil Chemical Analysis. Prentice Hall,Inc. EngewoodCliffs, NewJersey, USA.

Kanar E, Dengiz 0, 2015. Madendere Havzası Topraklarında Arazi Kullanım/Arazi Örtüsü ile Bazı Erozyon Duyarlılık İndeksleri Arasındaki İliş̧kinin Belirlenmesi. Türkiye Tarımsal Araştırmalar Dergisi, (2015) 2: 15.27.

Kemper WD, Rosenau RC, 1986. Aggregate stability and size distribution. Editor: Klute, A., Methods of Soil Analysis, Part I-Physical and Mineralocigal Methods, 2nd ed., SSSA Book Series No: 5, SSA and ASA, Madison, Wisconsin, pp. 425-442.

Lal R, 1988. Soil erosion research methods. Soil and Water Conservation Society, Netherland.

Leo Mic.ah WM, 1963. A rapid method for iestimating struetural stabi1Itty of soils. SoiI Sei. 96: 342-346.

Özdemir N, Gülser C, Ekberli İ, Özkaptan S, 2005. Toprak Düzenleyicilerinin Asit Toprakta Strüktürel Dayanıklllığa Etkisi. Atatürk Üniversitesi, Ziraat Fakültesi Dergisi, (2), 151-156.

Soil Survey Staff, 1992. Procedures for collecting soil samples and methods of analysis for soil survey. Soil Survey Invest. Rep. I. U.S. Gov. Print. Office, Washington D.C. USA.

Soil Survey Staff, 1993. Soil Survey Manual, USDA. Handbook No: 18 Washington D.C.

Turgut B, Aksakal EL, 2010. Fiğ Samanı ve Ahır Gübresi Uygulamalarının Toprak Aşınım Parametreleri Üzerine Etkileri. Artvin Çoruh Üniversitesi Orman Fakültesi Dergisi, 11 (1):1-10. 